\title{
Effects of Intervention on Maternal Skill in Positioning and Attachment for Successful Breastfeeding
}

\author{
ASMA FERDOUSI ${ }^{1}$, MAINUDDIN AHMAD $^{2}$, RASHEDA SAMAD ${ }^{3}$
}

\begin{abstract}
Background: Correct positioning and attachment play a crucial role in the successful establishment and maintenance of breast feeding. Objective of this study was to determine the effectiveness of immediate postnatal training of the mothers on their practice of proper positioning and attachment during breast feeding.

Material and Methods: This one group pretest-posttest quasi-experimental study was conducted at the Department of Pediatrics and Department of Obstetrics and Gynecology of Chittagong Medical College Hospital from January 2006 to June 2006. Three hundred mothers were evaluated for breast feeding position and attachment within 6 hours following normal delivery with a questionnaire and observational checklist. Then they received training on correct positioning and attachment for successful breastfeeding. Post training effect was evaluated by assessing mothers' practice on $7^{\text {th }}$ postnatal day among 256 mothers. Pre training and post training data were analyzed with SPSS-16 and McNemar test was done to see the difference.
\end{abstract}

Results: Out of 256 mothers only $22.3 \%$ were first time mother and about $40 \%$ of them had 1-2 children. Majority (84.4\%) of them knew about the benefits of breast feeding though one third (36.3\%) of them favored pre-lacteal feeding. Statistically significant improvement in all components of position and attachment for breast feeding was found after intervention.

Conclusion: The study results showed that immediate postnatal intervention towards correct positioning and attachment were highly effective for successful breast feeding.

Key words: Breast feeding, position, attachment

\section{Introduction:}

Breast feeding is the gold standard of infant feeding. ${ }^{1}$ In 1990 the Innocent Declaration to promote breast feeding worldwide was made by the $\mathrm{WHO}$ and UNICEF. Exclusive breastfeeding in the first 6 month of life and breastfeeding along with safe and nutritionally adequate complementary food thereafter up to 2 years of age and beyond play a pivotal role in child health. ${ }^{2}$

1. Assistant Professor (Pediatrics), Chittagong Medical College, Chattogram.

2. Professor and Head of Pediatrics, Universal Medical College, Dhaka.

3. Professor of Pediatrics, Chittagong Medical College, Chattogram.

Correspondence: Dr. Asma Ferdousi, Assistant Professor, department of Pediatrics, Chittagong Medical College, Chattogram. aferdousi71@gmail.com Cell: 01824825800

Submitted: 6/04/2019
Normal breastfeeding requires production and release of appropriate amount of milk from the breast and ability of the baby to remove the milk from the breast with effective suckling. The manner in which the baby is attached at the breast will determine how successfully these two elements go together. ${ }^{3}$ It is also observed that most breastfeeding difficulties can be avoided if good attachment and positioning are achieved at the first and early feeds. ${ }^{4}$ An effective sucking technique is considered important to establish breastfeeding, ensure milk transfer, and prevent breastfeeding problems. ${ }^{5,6}$ Study conducted at different tertiary care hospitals of Bangladesh revealed that, main problem related to breastfeeding were poor positioning and attachment $(64.4 \%)$ and insufficient breast milk (43.6\%) complained by the mothers ${ }^{7}$ only $43.1 \%$ of lactating mother were holding the baby properly while feeding ${ }^{8}$ and $2 \%$ of the 
mothers could not feed their babies due to lactation failure. ${ }^{9}$ The commonest problem among lactating mother was low milk production due to poor attachment and position. ${ }^{10,11}$ Cochrane review reported that, antepartum and postpartum interventions are effective in increasing breast feeding duration. ${ }^{12}$ This study was conducted to determine the effectiveness of immediate postnatal training of the mothers on their practice of proper positioning and attachment during breast feeding.

\section{Materials and Methods:}

This one group pretest-posttest design quasiexperimental study was conducted in the department of paediatrics and department of Obstetrics and Gynecology, Chittagong Medical College Hospital from January 2006 to June 2006 after obtaining approval from the ethical review committee of Chittagong Medical College. The study was conducted among mother having a full term normal baby with normal delivery and initiated breast feeding. Any mother with instrumental delivery, sick/preterm/ post term or low birth weight baby, sick mother, mother who refused to take part in the study were excluded. Moreover, those mothers who were observed to fulfill all the criteria for proper positioning and attachment during breast feeding were also excluded from this study. Total 300 nursing mother were enrolled in this study. Informed written consent was obtained from each mother before enrollment. The data was collected using a predesigned and pretested semi-structured questionnaire, which had a component of observer checklist adopted from a standard module on integrated management of neonatal and childhood illnesses ${ }^{13}$ for correct "breastfeeding attachment and positioning" technique. The criteria for correct baby positioning included the following: whole body turned to mother, body closed to mother, ear and shoulder in same plane, and supporting whole baby's body. The criteria of correct attachment include the following: mouth wide open, chin touched breast, lower lip turned outwards and majority of areola inside baby's mouth. The questionnaire also had items to collect information regarding age, number of children, residence, level of education, knowledge and attitude about breast feeding.

Investigators observed position and attachment during breast feeding and was documented in checklist while maintaining the privacy of mothers. If there was any problem, investigator informed the advantages of exclusive breast feeding and showed the nursing mother wall chart and breast feeding manual containing pictures showing technique of breast feeding and helped the nursing mother practically to correct the gaps. Mothers were requested to come after seven days with the baby to assess the effect of intervention and that time again technique of positioning and attachment during breastfeeding were documented. The pair which behaves normally during the act of breast feeding was given simple tips for healthful living. Data were analyzed using SPSS, version 16. McNemar test was used to determine if there were differences on pre and post test data. $p$ value less than 0.05 was accepted as significant in this study.

\section{Results:}

Though 300 mothers were enrolled initially but finally 256 women were available for post intervention evaluation and further analysis. Among those 256 mothers mean age was $29.96 \pm 9.34$ years ranging from 15 years to 55 years. Nearly half of them were from both rural $(50.8 \%)$ and urban $(49.2 \%)$ setting. Only $22.3 \%$ subjects were first time mother and $77.7 \%$ had single or more previous child. (Table I).

Table I

Baseline characteristics of the nursing mother $(n=256)$

\begin{tabular}{|c|c|c|c|}
\hline Variables & Label & Frequency & Percent \\
\hline \multicolumn{4}{|l|}{$\overline{\text { Age (years) }}$} \\
\hline$<20$ years & 26 & 10.2 & \\
\hline 20-24 years & 57 & 22.3 & \\
\hline $25-29$ years & 64 & 25.0 & \\
\hline 30-34 years & 36 & 14.0 & \\
\hline 35-39 years & 24 & 9.4 & \\
\hline$\geq 40$ years & 49 & 19.1 & \\
\hline Mean Age $( \pm S D)$ & \multicolumn{2}{|c|}{$29.96( \pm 9.34)$} & \\
\hline \multicolumn{4}{|l|}{ Level of education } \\
\hline Illiterate & 72 & 28.1 & \\
\hline Class I-V & 49 & 19.1 & \\
\hline Class VI to X & 89 & 34.8 & \\
\hline Class XI and ab & e 46 & 18.0 & \\
\hline \multicolumn{4}{|l|}{ Residence } \\
\hline Rural & 130 & 50.8 & \\
\hline Urban & 126 & 49.2 & \\
\hline \multicolumn{4}{|c|}{ Number of previous child } \\
\hline None & 57 & 22.3 & \\
\hline $1-2$ & 100 & 39.0 & \\
\hline $3-4$ & 64 & 25.0 & \\
\hline$>4$ & 35 & 13.7 & \\
\hline
\end{tabular}


Table II shows that only 40/256 (15.6\%) mother did not have knowledge about the advantage of breast milk. Around $70 \%$ of the mother favored colostrum as an essential food for a newborn though 93/256 $(36.3 \%)$ still preferred pre-lacteal food. Statistically significant post intervention improvement was found in all four component of positioning for breast feeding (shown in Table III). Post intervention improvement was also found in all four component of proper attachment for breast feeding and which was statistically highly significant (shown in Table IV).
Table II

Distribution of the respondents by their knowledge and attitude about breast feeding $(n=256)$

\begin{tabular}{lcc}
\hline Variable & Frequency & Percentage \\
\hline Knows about advantage of breast milk & \\
No & 40 & 15.6 \\
Yes & 216 & 84.4 \\
Favors Pre-lacteal food & & \\
No & 163 & 63.7 \\
Yes & 93 & 36.3 \\
Favors Colostrums & & \\
No & 77 & 30.1 \\
Yes & 179 & 69.9 \\
\hline
\end{tabular}

Table III

Pre and Post Intervention difference in the practice regarding position of baby during breast feeding $(n=256)$

\begin{tabular}{lccc}
\hline Criteria & \multicolumn{2}{c}{ Frequency (\%) of the women } & p value* \\
& Before intervention & After intervention & \\
\hline $\begin{array}{l}\text { Whole body turned to mother } \\
\text { No }\end{array}$ & $173(67.6 \%)$ & $42(16.4 \%)$ & 0.004 \\
$\quad$ Yes & $83(32.4 \%)$ & $214(83.6)$ & \\
Body closed to mother & & & \\
$\quad$ No & $229(89.5 \%)$ & $26(10.2 \%)$ & 0.001 \\
$\quad$ Yes & $27(10.5 \%)$ & $230(89.8 \%)$ & \\
Ear \& shoulder in same plane & & & \\
$\quad$ No & $231(90.2 \%)$ & $37(14.5 \%)$ & 0.001 \\
$\quad$ Yes & $25(9.6 \%)$ & $219(85.5 \%)$ & \\
Supporting whole baby's body & & & \\
$\quad$ No & $206(80.5 \%)$ & $38(14.8 \%)$ & 0.008 \\
$\quad$ Yes & $50(19.5 \%)$ & $218(85.2 \%)$ & \\
\hline
\end{tabular}

$p$ values were obtained from McNemar test.

\section{Table IV}

Pre and Post Intervention difference in the in the practice regarding attachment of baby on mother's breast in course of breast feeding $(n=256)$

\begin{tabular}{lccc}
\hline Criteria & \multicolumn{2}{c}{ Frequency (\%) of the women } & p value \\
& Before intervention & After intervention & \\
\hline Mouth wide Open & & & \\
$\quad$ No & $231(90.2 \%)$ & $42(16.4 \%)$ & 0.001 \\
$\quad$ Yes & $25(9.8 \%)$ & $214(83.6)$ & \\
Chin touched breast & $230(89.8 \%)$ & $47(18.4 \%)$ & 0.001 \\
$\quad$ No & $26(10.2 \%)$ & $209(81.6 \%$ & \\
$\quad$ Yes & $230(89.8 \%)$ & $43(16.6 \%)$ & 0.001 \\
Lower Lip turned outwards & $26(10.2 \%)$ & $213(83.2 \%)$ & \\
$\quad$ No & $227(88.7 \%)$ & $121(47.3 \%)$ & 0.001 \\
Yes & $29(11.3 \%)$ & $135(52.7 \%)$ & \\
Majority of areola inside baby's mouth & & & \\
$\quad$ No & & \\
Yes & & & \\
\hline
\end{tabular}

$p$ values were obtained from McNemar test. 


\section{Discussion}

Impact study on baby friendly hospital initiative of breast feeding foundation documented 'lack of knowledge about colostrums,' 'lack of proper training as to how a child should be given breast milk' as constrain of exclusive breast feeding. ${ }^{14}$ In this study only $15.6 \%$ of the mother didn't have knowledge about the advantage of breast feeding, and maximum number $(69.9 \%)$ of mother favored colostrum as an essential food for a newborn which actually reflected the effective campaign in favor of breast feeding in our country though still $36.3 \%$ preferred pre-lacteal feeding. Education has significant influence over people's perception, awareness, knowledge and practice of certain habits as well, which requires adequate attention to reduce bias. ${ }^{15}$ Experience of nursing of previous child facilitate the mothers to learn skills for attending neonates, particularly those who had multiple alive children and those had contact with health personnel in their previous pregnancies and lactation. In this study $77.7 \%$ of mothers had single or more previous child, still there was marked gap considering both position and attachment for breast feeding. At 1 st visit in our study revealed positioning and attachment as a major problem faced by mothers which corresponds to the finding of previous studies in Bangladesh. ${ }^{7,8}$

Before intervention both appropriate positioning and attachment for breast feeding among majority of the mother was found very poor. But after intervention statistically significant improvement was found in all four component of positioning for breast feeding along with improvement in all four component of proper attachment also. This promising positive effect of intervention is the only key for successful breastfeeding. Ma YY et al. ${ }^{16}$ and Wallace LM et al. ${ }^{17}$ both in their study found that video training for mother was effective methods of successful breast feeding. Henderson AM et al. also found that assisting nursing mother by midwives to establish breastfeeding was successful. ${ }^{18}$ Like those other studies this study also supports that appropriate intervention on nursing mother is the key for successful breastfeeding.

\section{Conclusion:}

Mothers irrespective of the age, locality, parity and educational status had lacking in technique of proper positioning and attachment in breastfeeding. Intervention on nursing mother is highly effective for improving positioning and attachment thereby successful breastfeeding.

\section{References}

1. Editorial, Breastfeeding resurgence in Bangladesh Journal, Bangladesh College of Physicians and Surgeons 1995; 14: 1-2.

2. World Health Organization \& UNICEF. Global strategy for infant and young child feeding. http:// www.who.int/nutrition/ publications/infantfeeding/ 9241562218/en.

3. Breastfeeding management and promotion in a baby friendly hospital, UNICEF, New York NY 10017 U.S.A. Jan, 1993: 4-56.

4. Vinther T, Helsing E. Breastfeeding: How to Support Success: A Practical Guide for Health Workers. Copenhagen, Denmark: World Health Organization, Regional Office for Europe; 1997:10-12.

5. Inch S. Breastfeeding problems: prevention and management. Community Pract. 2006;79:165-67.

6. Renfrew M, Lang S. Interventions for improving breast feeding technique (Cochrane Review). In: The Cochrane Library, Issue 4: Oxford Update Software, 1999.

7. Afroza S, Begum R. Breastfeeding corner support in promotion of breastfeeding for infants. Bangladesh Journal of Child Health, 2003; 27:38-42.

8. Halder A. Breastfeeding procedure among mother attending the maternity and child health training institute. Breastfeeding Research Compendium, B.B.F. Dhaka 1991: 59-60.

9. Molla MNH. Feeding Practices of Infants Attending Azimpur MCHTI Feb.- March 1983, Report published in Breastfeeding Research Compendium, B.B.F Dhaka, 1983: 63.

10. Uddin HIMN, Islam MN, Islam MA, Feeding practice in infants attending children out patient department of IPGMR, Dhaka, Report published in Breastfeeding Research Compendium, B.B.F. Dhaka, 1983: 63-4.

11. Nahar K. Lactation Management Clinic in Mymensingh Madical College Hospital. Paper presented in 4th National conference and Scientific Seminar, of Bangladesh Neonatal Forum, on 24th Nov. 2004.

12. Sikorski J, Refrew M. Support for breastfeeding mothers (Cochrane Review). In: The Cochrane Library, Issue 4: Oxford Update Software, 2000.

13. WHO, UNICEF. Integrated Management of Neonatal and Childhood IIIness (Training modules for Medical Officers). New Delhi, India: Government of India, Ministry of Health and Family Welfare; 2003.

14. SODEV Consults Limited, B.B.F. Final Report on Impact Study on Baby Friendly Hospital Initiative, 
Training and Monitoring. Paper published in Breastfeeding Research Compendium, B.B. F., Dhaka. August 1996: 12-13.

15. Foege WH. Social determinants of health and healthcare solutions. Public Health Rep. 2010; 125: 8-10.

16. Ma YY, Wallace LL, Qiu LQ, Kosmala-Anderson J, Bartle N. A randomized controlled trial of the effectiveness of a breastfeeding training DVD on improving breastfeeding knowledge and confidence among healthcare professionals in China. BMC Pregnancy Childbirth. 2018;18: 80.
17. Wallace LM, Ma Y, Qiu LQ, Dunn OM. Educational videos for practitioners attending Baby Friendly Hospital Initiative workshops supporting breastfeeding positioning, attachment and hand expression skills: Effects on knowledge and confidence. Nurse EducPract. 2018; 31:7-13.

18. Henderson AM, Pincombe J, Stamp GE. Assisting women to establish breastfeeding: exploring midwives' practices. Breastfeed Rev. 2000; 8: 11-17. 